\title{
VIDA COTIDIANA Y PARTICIPACIÓN POLÍTICA: "LA MARCHA DE LAS ESCOBAS" EN LA HUELGA DE INQUILINOS, BUENOS AIRES, 1907
}

\author{
INÉS YUJNOVSKY \\ El Colegio de México (México)
}

\section{INTRODUCCIÓN}

En 1895 la población de Argentina se había duplicado en 25 años y lo haría de nuevo en 20 años más. Debido a la inmigración el país pasó de tener dos millones de habitantes en 1869 a ocho millones en 1914. Los políticos liberales del siglo XIX tenían grandes esperanzas en los efectos positivos que producirían los inmigrantes al convertirse en pequeños propietarios rurales; sin embargo, la masa de inmigrantes fue absorbida por ocupaciones propias de las ciudades. Ya en 1914, Buenos Aires concentraba el $20 \%$ de la población total del país y el $53 \%$ de la población era urbana ${ }^{1}$.

Las ciudades no estaban preparadas para esa explosión demográfica y uno de los principales problemas fue el de la vivienda. A falta de políticas públicas, el verdadero distribuidor de recursos del desarrollo urbano fue el mecanismo de precios de mercado. El conventillo y la casa de inquilinato fueron las respuestas a la creciente demanda de vivienda ${ }^{2}$. James Scobie ha analizado las transformaciones urbanas de Buenos Aires entre 1870 y 1914, explicando que a partir de 1900 las mejoras en los tranvías permitieron el traslado de los trabajadores hacia los suburbios, lo que implicó el nacimiento del fenómeno del «barrio» como núcleo de una nueva sociabilidad ${ }^{3}$.

1. Es interesante señalar que la Ciudad de México, la más importante durante el período colonial en Hispanoamérica, contaba con una población de 470.000 habitantes en 1910, habiéndose duplicado desde 1887 pero siendo su población casi 1/4 de la de Buenos Aires. Para la población de México, véase Méndez Rodríguez, Alejandro: Debate inquilinario en la ciudad de México durante el siglo XX, México, UNAM, 2001.

2. El trabajo clásico respecto a políticas públicas de vivienda, del período 1880-1930, sigue siendo el de Yujnovsky, Óscar: "Políticas de vivienda en la ciudad de Buenos Aires», Desarrollo Económico, 14-54 (1974), pp. 327-372.

3. Scobie, James: Del centro a los barrios 1870-1910, Buenos Aires, Solar/Hachette, 1977.

Feminismo/s, 3, junio 2004, pp. 117-134 
Diversos autores han señalado que una de las características de las viviendas en el período de 1880 a 1930 era el fuerte contraste entre ricos y pobres. Las élites estaban influenciadas por la moda europea, por lo que sus viviendas imitaban los palacetes de estilo francés, en los que vivían cuatro o cinco personas de una familia rica con gran cantidad de sirvientes. A partir de la peste de 1871 la zona preferida por las familias patricias dejó de ser el centro de la ciudad y éstas se ubicaron en barrios alejados de los inmigrantes, los "pobres» y las enfermedades.

En el lado opuesto de la escala social se encontraba el conventillo: la vivienda para los sectores populares, en especial para los recién llegados inmigrantes. Los conventillos eran antiguas casonas de sectores pudientes que se mudaron hacia las nuevas zonas residenciales, al norte de la ciudad ${ }^{4}$. En cada conventillo podían vivir hasta 350 personas. Se trataba de un albergue considerablemente barato en el que habitaban con alto nivel de hacinamiento lavanderas, costureras, sirvientes, jornaleros pobres, carpinteros, albañiles, zapateros, sastres y empleados de comercio, entre otros.

El conventillo funcionó como un verdadero ambiente de aculturación de la amplia gama de nacionalidades de las capas pobres inmigrantes que allí convivieron con sus diferentes lenguas y modos de vida. Si bien los italianos y españoles representaron el primer y segundo grupo inmigratorio respectivamente, se ha demostrado la presencia de numerosas otras nacionalidades (checos, polacos, judíos rusos, sirio-libaneses, franceses, ingleses, alemanes) en las áreas centrales ocupadas por conventillos ${ }^{5}$. En este período, el costo de vida de los trabajadores aumentó considerablemente y en particular el costo de la vivienda. En 1886 el alquiler representaba un 16\% del salario de jornaleros y artesanos; en 1912 representaba un $30 \% 6$.

La huelga de inquilinos de 1907 ha sido analizada desde distintos puntos de vista. Los estudios interesados en los problemas de la inmigración han señalado la huelga de inquilinos como un ejemplo de los conflictos existentes. En los últimos años, la historiografía ha recuperado las problemáticas regionales y la existencia de comunidades con identidades étnicas que se resistieron a desaparecer en el seno de la sociedad receptora. En relación a los conventillos se ha visto que algunos de ellos eran ocupados por mayoría de inmigrantes de una misma nacionalidad ${ }^{7}$. Desde la perspectiva de la historia urbana, con interés en la

4. Hardoy señala que «la construcción de conventillos o la transformación de casas en inquilinatos fue un excelente negocio durante las dos últimas décadas del siglo XIX y las dos primeras del XX». También concluye que la mayoría de los propietarios eran comerciantes, importadores y empresarios extranjeros con actividades diversificadas. En general, las elites vendían sus antiguas residencias o contrataban administradores (HARDOY, Jorge Enrique: "La vivienda popular en el Municipio de Rosario a fines del siglo XIX. El censo de conventillos de 1895» en Diego Armus (comp.): Sectores populares y vida urbana, Buenos Aires, CLACSO, 1984, pp. 77-105).

5. SCoBIE, James: Del centro a..., op. cit.

6. ScobIE, James: From Plaza to Suburbs, 1870-1910, New York, Oxford University Press, 1974, pp. 266-268.

7. Сівоті, Emma: «Del inmigrante al ciudadano», en Mirta Z. Lobato: Nueva Historia Argentina. Tomo 5: El progreso, la modernización y sus límites (1880-1916), Buenos Aires, Sudamericana, 2000, pp. 365-408. 


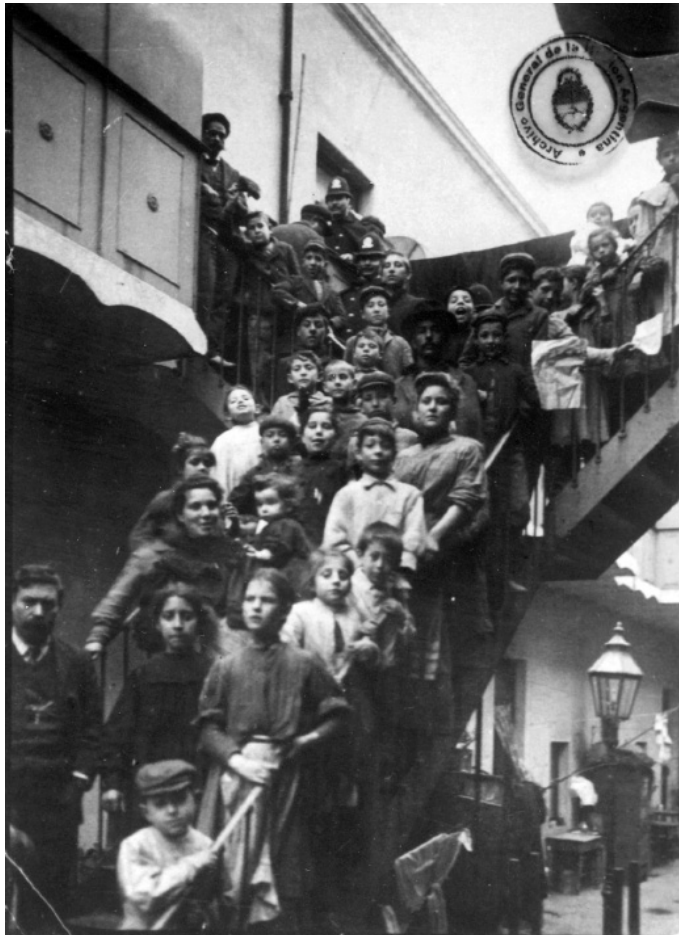

Huelga de conventillos, Colección Caras y Caretas, Archivo General de la Nación Argentina (AGN), 1907. cultura popular, los trabajos se han concentrado en las características materiales del conventillo ${ }^{8}$. Estos trabajos mencionan la huelga de inquilinos pero no como centro de su interés. El único trabajo dedicado exclusivamente a la huelga es el de Juan Suriano quien analiza las formas de organización y el rol del anarquismo9. Es importante señalar que ningún trabajo se ha centrado en la participación femenina.

Considero que las actuales perspectivas y las nuevas preguntas provenientes de la historia de la vida cotidiana pueden aportar aspectos poco profundizados hasta ahora. Norbert Elias propone el estudio de lo rutinario en oposición a lo excepcional. El énfasis en la vida cotidiana ha destacado la importancia de nuevos temas como la familia, el hogar, los

gestos, que habían sido considerados objetos menores de estudio. Lo cotidiano no sólo se vive, también se piensa y ello ha conducido a preguntas sobre lo que las sociedades pensaban respecto a la muerte, al tiempo, a los espacios donde se vivía la mayor parte de la vida o a los espacios de sociabilidad como el café, la plaza o el mercado. Por ello (aunque las huelgas en este período eran formas de demanda legítimas bastante habituales) pone de manifiesto concepciones acerca de la vivienda, el género y la familia.

La historia de la vida cotidiana surgió como un concepto más amplio que la historia de la vida privada, debido a que esta última perspectiva enfatizó que las definiciones de lo público y lo privado son relativas ya que tienen acepciones diferentes según el período histórico que se considere ${ }^{10}$. Desde esta perspectiva, es posible analizar el rol de hombres y mujeres en los espacios públicos y plantear si es posible hablar de ámbitos femeninos distintos a los masculinos. ¿Las mujeres permanecieron silenciosas en sus hogares mientras que los hombres organizaban la huelga? ¿O se puede proponer otra perspectiva?

8. Por ejemplo Armus, Diego (comp.): Sectores populares..., op. cit.

9. Suriano, Juan: La huelga de inquilinos de 1907, Buenos Aires, CEAL, 1983.

10. Duby, Georges (ed.): Historia de la Vida Privada, Madrid, Taurus, 1987. 


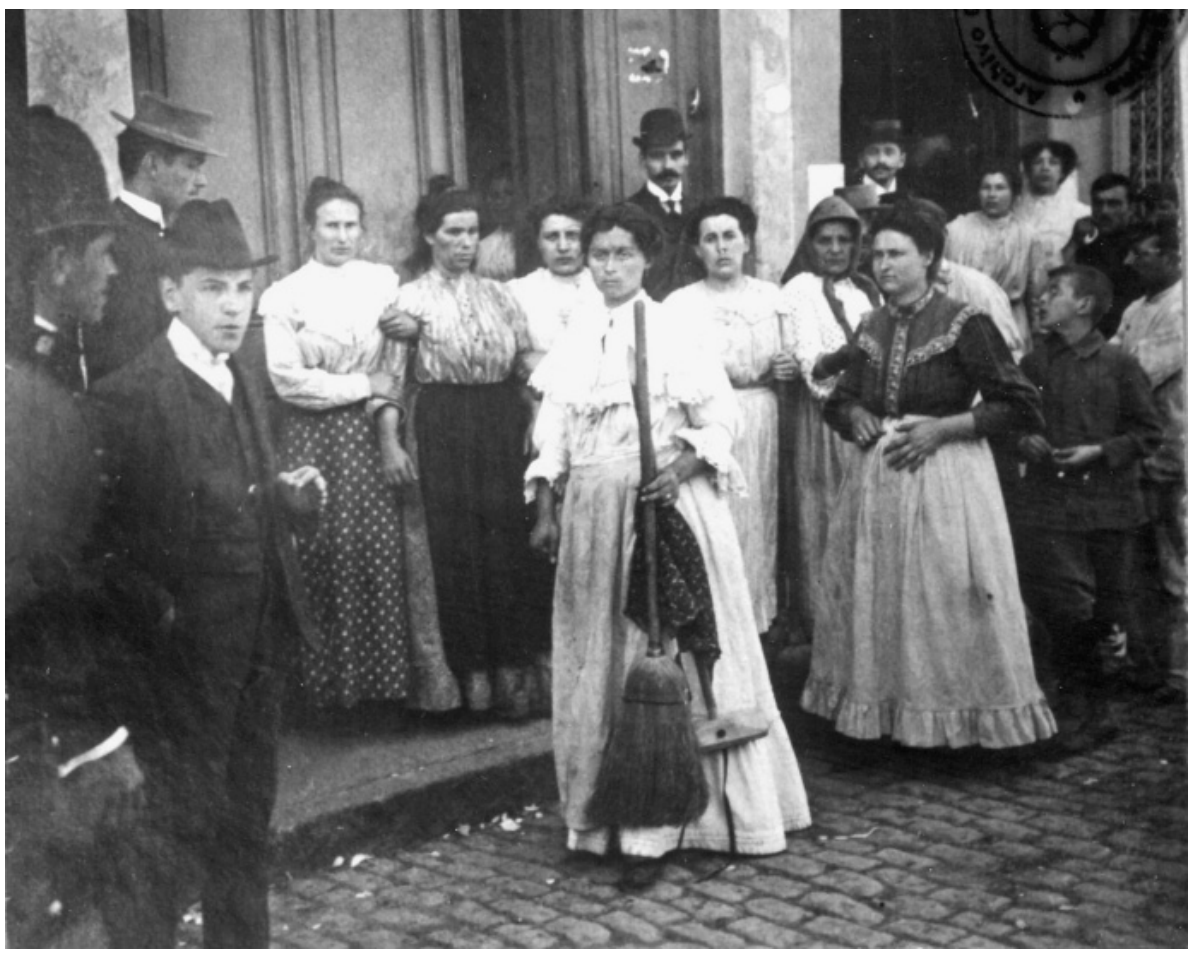

«Marcha de las escobas». Huelga de conventillos, Colección Caras y Caretas, AGN, 1907.

Me propongo estudiar la visión de la prensa de la época respecto a las condiciones de vida en los conventillos y observar el rol de las mujeres en las reivindicaciones vinculadas con la vida cotidiana. Busco analizar los distintos puntos de vista, el debate público que suscitó el conflicto y cómo la visibilidad que impulsaron las mujeres respecto a problemas cotidianos se incorporó a la esfera pública a través de la prensa periódica para discutir diferentes soluciones a las malas condiciones de vida que existían en los conventillos. El debate que se expresa con la huelga de inquilinos evidencia las tensiones existentes respecto a los conceptos de vivienda, familia y género.

En el momento crítico de una huelga busco explorar los procesos de cambio insertos en la temporalidad más larga de la vida cotidiana. La vida cotidiana suele estar sujeta a largos períodos en los que se producen pocas modificaciones; en períodos en que la vida política se ve sujeta a profundas transformaciones, aspectos que van desde la sexualidad y el género, la salud o la comida hasta las concepciones respecto a códigos, estereotipos, prejuicios y virtudes, continúan concibiéndose de la misma manera que antes. En el caso de la huelga de inquilinos las formas de vida cotidiana de los sectores populares estaban siendo profundamente modificadas. El proceso de inmigración de la Europa 




Caras y Caretas, año X, n 469, 28 de septiembre de 1907.

rural al Buenos Aires urbano, sumado a los procesos de modernización en el cambio de siglo transformaron la vida de la gente para siempre ${ }^{11}$.

\section{EL DESARROLLO DE LA HUELGA}

En Buenos Aires, en 1907, se produjo una huelga de inquilinos que reclamaba la disminución de los precios de alquiler y la prensa cubrió con amplitud los sucesos. Los diarios comentaban las malas condiciones de vida, las medidas del gobierno y los acontecimientos diarios que protagonizaban los participantes del conflicto. Entre ellos los más destacados eran las luchas entre policías y mujeres en los desalojos. Pero hubo un hecho que también mereció la atención: «la marcha de las escobas». En su gran mayoría niños y mujeres recorrieron las calles del barrio de La Boca levantando las escobas "para barrer a los caseros».

En agosto de ese año, la Municipalidad de Buenos Aires anunció que el año siguiente aumentaría los impuestos. Frente a esta noticia, los propietarios

11. El período en el que se incluye la huelga de inquilinos comienza en 1871, año decisivo ya que una fuerte epidemia de fiebre amarilla implicó transformaciones en las zonas habitacionales preferidas por las elites, dejando espacios céntricos a los sectores populares. Hacia 1920 la conformación de los barrios había disminuido la importancia de los conventillos como forma dominante de vivienda popular. 
y arrendatarios subieron los precios de los alquileres bajo la excusa de cubrir los nuevos desembolsos. Sin embargo, los incrementos se produjeron antes de la subida de impuestos; además, el periódico La Nación señalaba que «los propietarios aumentan el precio del alquiler bastante más que el aumento de impuestos ${ }^{12}$. La gran demanda habitacional producida por los contingentes migratorios que se asentaban en el puerto de Buenos Aires, más que la excusa de los propietarios, elevaba los precios de las rentas.

A fines de agosto, los moradores de un conventillo se declararon en huelga rehusando pagar el alquiler. Otros conventillos siguieron su ejemplo, presentando a los encargados pliegos de condiciones, en los cuales pedían rebajas de los alquileres y otras demandas para mejorar la calidad de las viviendas. Los huelguistas formaron un comité central que distribuyó propaganda, buscó nuevas adhesiones y entró en contacto con los comités constituidos en otros barrios ${ }^{13}$. En el mes de octubre, el movimiento asumió proporciones imprevistas: 500 conventillos iniciaron el reclamo, pronto se extendió a otros barrios y a la ciudad de Rosario en la provincia de Santa Fe, llegando a adherirse unos 2000 conventillos. Se movilizaron unas 120.000 personas, lo que implicó un $10 \%$ de la población de la ciudad de Buenos Aires. Las sociedades de resistencia abrieron sus locales para reuniones de inquilinos. Mujeres y niños participaron ampliamente. Hacia fines de noviembre, el movimiento fue perdiendo fuerza, se llegó a acuerdos individuales, se introdujeron mejoras sanitarias y se plantearon algunas propuestas para la construcción de viviendas baratas. Pero en general los precios se mantuvieron en ascenso y la gradual desaparición de los conventillos no se dio por políticas públicas de vivienda sino por el traslado de los trabajadores a los suburbios ${ }^{14}$.

La huelga de inquilinos no fue un conflicto aislado, los movimientos de protesta también estallaron en Montevideo, Chile, Río de Janeiro, México, Glasgow y Nueva York ${ }^{15}$. En los casos mexicanos, 1922 fue un año en el que se declararon conflictos en Veracruz, México DF, Guadalajara y Mérida ${ }^{16}$. Jorge Durand analiza el conflicto de inquilinos en México tratando de insertarlo en un movimiento internacional más amplio ${ }^{17}$. Es interesante observar que la mayor fuerza de estos movimientos se dio en ciudades portuarias, que recibían gran-

12. La Nación, no 12152, 19 de septiembre de 1907, p. 8 (en Spalding, Hobart: La clase trabajadora argentina. Documentos para su historia, 1890-1912, Buenos Aires, Galerna, 1970, pp. 469-470).

13. Para un análisis de las formas de organización y de las tendencias políticas que apoyaron a los inquilinos véase Suriano, Juan: «La Huelga de inquilinos de 1907 en Buenos Aires», en Diego Armus (comp.): Sectores populares..., op. cit., pp. 201-232.

14. Esta es la propuesta central del trabajo de Scobie, James: Del centro a..., op.cit.

15. Para el caso chileno, véase EspinozA, Vicente: «La huelga de arriendos en 1925 en Santiago de Chile», en Diego Armus (comp): Sectores Populares..., op.cit.

16. Véase García Mundo, Octavio: El movimiento inquilinario en Veracruz, 1922, México, SepSetentas, 1976.

17. Véase Durand, Jorge: «Huelga nacional de inquilinos: los antecedentes del movimiento urbano popular en México", Estudios Sociológicos, VII-19 (1989), pp. 61-78. 
des flujos de inmigrantes y por lo tanto donde el desequilibrio entre vivienda y población fue más importante.

Por otra parte, se trata de un período de alta conflictividad social, que incluía huelgas en las distintas áreas artesanales e industriales: desde sastres, modistas, panaderos, tejedoras hasta los sectores de los ferrocarriles y el puerto. Sin embargo, salvo alguna de las huelgas generales como la de 1904, pocas de las movilizaciones del período tuvieron la fuerte repercusión de la huelga de inquilinos, llamando en la misma medida la atención de la prensa periódica del momento y de la historiografía posterior. En este sentido, considero que el fuerte impacto de este conflicto se debe a dos aspectos centrales: aunque el motivo inmediato de la "huelga» era la reducción de los precios de alquiler, los reclamos incluían aspectos centrales para mejorar la vida cotidiana de un alto número de habitantes de la ciudad, que a su vez repercutía en las condiciones de higiene de la ciudad. Éste fue uno de los debates más importantes que apareció en la prensa. El segundo motivo de la fuerte repercusión y simpatía a este movimiento fue la alta participación femenina que le dio características particulares.

Desde un punto de vista metodológico es importante señalar que el estudio de este tipo de conflictos otorga un conjunto de fuentes, producto de un intenso debate, que de otra forma permanecería oculto, permitiendo un acercamiento indirecto a las experiencias y a los deseos de los sujetos ante la vida cotidiana. La huelga de inquilinos de 1907 llamó la atención de diversos grupos sociales. Periódicos tan distintos como La Voz de la Iglesia, La Protesta, La Vanguardia, Caras y Caretas y La Nación ${ }^{18}$, con posturas ideológicas opuestas y apreciaciones diversas respecto al conflicto, coinciden en un aspecto: las deficiencias en las condiciones higiénicas de los conventillos.

\section{LAS CONDICIONES DE VIDA}

El primer aspecto que se menciona es el hacinamiento: las distintas fuentes indican un promedio de cinco a seis personas, llegando a diez $u$ once por habitación, en conventillos que iban desde 20 a 300 habitantes.

18. La Protesta fue el periódico anarquista con mayor difusión y continuidad del período. La Vanguardia fue el principal periódico socialista, que se publicó entre los años 1894 y 1955. La Nación comenzó su publicación en 1870, relacionada con la clase dirigente argentina; aunque aspiraba a situar su mirada por encima de los enfrentamientos, se trataba de prensa partidista. A partir de 1900 su director fue el ingeniero Emilio Mitre, reconocido por sus debates acerca de la importancia de las obras públicas. Un trabajo muy interesante acerca de este periódico es el de SidiCARO, Ricardo: La política mirada desde arriba. Las ideas del diario La Nación 1909-1989, Buenos Aires, Sudamericana, 1993. Caras y Caretas era una revista ilustrada que se publicó entre 1898 y 1939; como muchas revistas modernistas de la época se caracterizó por su enciclopedismo y cosmopolitismo. Se veía a sí misma como participante activa en una variedad de áreas, como patrón en las artes y como paladín de la verdad ante el crimen y la corrupción, comentarista en cuestiones obreras y expositor del progreso. Se la puede considerar como una exposición de Argentina en el cambio de siglo. Véase FrASER, Howard M.: Magazines and masks. Caras y Caretas as a reflection of Buenos Aires, 1898-1908, USA, Center for Latin American Studies Arizona State University, 1987. 


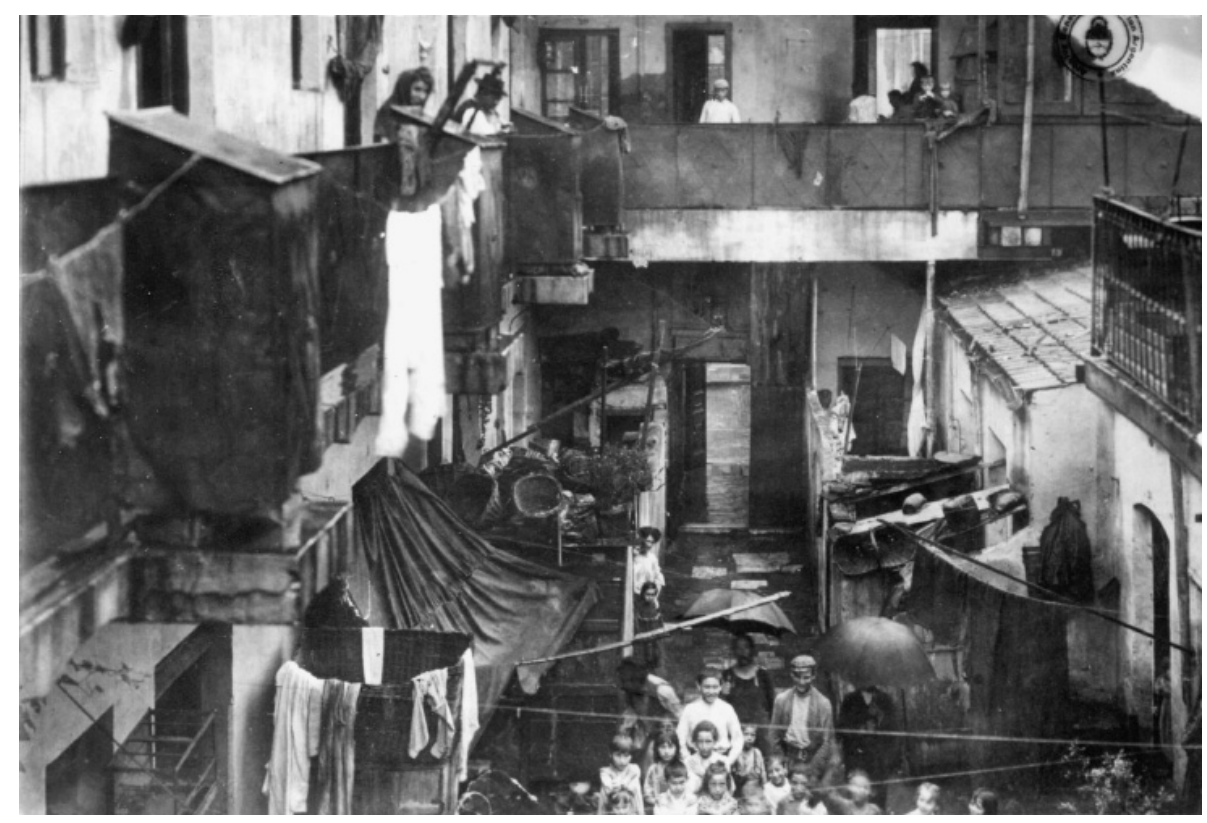

Huelga de conventillos. Colección Caras y Caretas, AGN, 1907.

La Protesta señalaba que era una «pocilga inmunda de un metro de ancho y uno y medio de alto ${ }^{19}$. Aunque la medida es exagerada, ya que la mayoría de las habitaciones medían entre cuatro y cinco metros, es interesante la imagen de una habitación más alta que ancha. La Vanguardia decía: «nuestro obrero paga una tercera parte de su salario por una covacha que más se parece a un chiquero que a una vivienda humana ${ }^{20}$. Ante un desalojo, $L a$ Voz de la Iglesia agregaba: "fueron sacados los pobres cachivaches de las humildes covachas ${ }^{21}$. La idea de inmundas habitaciones se repetía continuamente; chiqueros, covachas, ratoneras: desde los socialistas hasta los católicos asociaban los conventillos con las viviendas de animales. Hubo denuncias de la existencia de palomares y criaderos de gallinas en los conventillos ${ }^{22}$. En 1907, la Municipalidad de Rosario pidió una reforma de la ordenanza sobre conventillos e inquilinatos para prohibir su existencia en terrenos que contuvieran tambos o caballerizas ${ }^{23}$. Es evidente la supervivencia de estas prácticas, aunque existía una valoración negativa al respecto y la legislación municipal prohibía la convivencia de animales junto a las personas.

19. La Protesta, $n^{\circ} 1154,4$ de octubre de 1907, p. 1 (en Spalding, Hobart: Op.cit., p. 485).

20. "El problema de la habitación", La Vanguardia, año XIV, n 618, 24 de noviembre de 1907, p.

1 (en Reinoso, Roberto (comp): La Vanguardia. Selección de textos (1894-1955)], Buenos Aires, CEAL, 1985, p. 58).

21. La Voz de la Iglesia, $n^{\circ} 7308,1$ de octubre de 1907, p. 1 (en Spalding, Hobart: Op. cit., p. 479).

22. El Tiempo, n 2624, 21 de enero de 1903, p. 2 (en Spalding, Hobart: Op. cit., pp. 456-457).

23. La Nación, no 12152, 19 de septiembre de 1907, p. 7 (en Spalding, Hobart: Op. cit., pp. 469470). 
No sólo la prensa obrera y la Iglesia denunciaban las malas condiciones de las viviendas, también las clases altas, que normalmente se oponían a las huelgas obreras, estaban de acuerdo con los reclamos iniciados por los inquilinos. La Nación señalaba que «de una gira efectuada por ciertos barrios de la ciudad situados en los suburbios, se llega a la conclusión de que la gente obrera tiene mucha razón en quejarse de las viviendas que ocupan por sus condiciones malsanas y alquileres excesivos ${ }^{24}$.

Otro aspecto ampliamente denunciado se refiere a los baños. En su informe de 1904 Bialet Masse comentaba que «en Córdoba no ha entrado la civilización de las letrinas ${ }^{25}$. También en relación al hacinamiento, La Protesta denunciaba la existencia de un conventillo con 300 habitantes y dos baños ${ }^{26}$. El agua también era un problema, un reglamento indicaba que «es prohibido lavado para afuera como igualmente dejar abiertas canillas, derramar agua o cualquier otra materia que moleste a la salud y limpieza». Deben haber sido actividades bastante habituales que generaban problemas para que fuera necesaria su reglamentación. También La Protesta denunciaba: «en verano nadie puede bañar a sus niños ${ }^{27}$.

A partir de este cuadro de hacinamiento, malas condiciones higiénicas, falta de agua y de luz, se generalizaron ideas que asociaban la falta de higiene a la degradación moral; por ejemplo Bialett Masse consideraba que

"allí las suciedades en contacto, las pasiones acechando pared por medio, en lucha y contacto diario, las peleas de las vecinas enconando odios entre los hijos desde la infancia, el cambio continuo quitando la idea de estabilidad y matando el patriotismo, ese es el conventillo, foco de todas las ruindades ${ }^{28}$.

La Vanguardia iba todavía más lejos, calificaba de «antros de vicio, degradación y enfermedad, los conventillos son peor que el infierno de Dante (...) inmundo, inmoral y antihigiénico ${ }^{29}$.

El lenguaje imperante estaba vinculado a concepciones positivistas del darwinismo social y a imaginarios respecto a la salud y la enfermedad trasladados a la esfera de la sociedad ${ }^{30}$. A fines del siglo XIX, las malas condiciones

24. «Reportaje de Rosario sobre las casas de inquilinato», La Nación, n 12161, 28 de septiembre de 1907, p. 7 (en Spalding, Hobart: Op. cit., p. 490).

25. Informe de MASSE, Bialett: El estado de las clases obreras argentinas, Córdoba, Universidad Nacional de Córdoba, 1968 [1904], p. 219.

26. "Carta de un inquilino», La Protesta, n 1152, 2 de octubre de 1907, p. 1 (en Spalding, Hobart: Op. cit., pp. 480-481).

27. La Protesta, n 536, 30 de mayo de 1905, p. 2 (en Spalding, Hobart: Op. cit., p. 455).

28. MASSE, Bialett: Op. cit., p. 245.

29. «El problema de la habitación», La Vanguardia, año XIV, n 618, 24 de noviembre de 1907, p. 1 (en Reinoso, Roberto (comp): Op. cit., p. 58).

30. Óscar Terán explica que el éxito del positivismo obedece a que se trató de una reflexión acerca de los efectos no deseados del proceso de modernización. La mirada de los intelectuales quedó fascinada por la teoría social-darwinista sobre los factores raciales (supervivencia del más apto) que presuntamente explicarían el retraso y las frustraciones modernizantes. Véase TeRÁn, Oscar: Vida intelectual en el Buenos Aires fin de siglo [1880-1910]: Derivas de la cultura científica, Buenos Aires, Fondo de Cultura Económica, 2000. 
sanitarias amenazaban la salubridad de la población por lo que comenzó a prestarse una creciente atención a la educación de los trabajadores, las obras de saneamiento, el aire puro, los espacios verdes y la atención médica. Los conventillos fueron uno de los blancos preferidos para demostrar cómo las malas condiciones de higiene, frecuentemente provocadas por los mismos propietarios «inescrupulosos», acrecentaban las enfermedades infecto-contagiosas. El higienismo estimuló la difusión de información así como la implementación de medidas y códigos que pretendían modificar las conductas de la vida cotidiana. Desde la desinfección de billetes, la quema de muebles, la importancia del barrido con agua para no levantar polvo, hasta la prohibición del uso de alfombras o de escupir en la calle y en zonas públicas pretendían cambiar hábitos de la vida cotidiana. En algunos casos fueron lentamente efectivas, y a veces sólo un código más para evadir.

No hay duda de que los habitantes de los conventillos gozaban de acceso a lugares de trabajo y servicios, a pesar de tener malas condiciones de vivienda, por ello se comprende la gran demanda de este tipo de alojamiento. Además existió una alta movilidad entre conventillos y como se puede observar en las fotografías había bastante diversidad. No era lo mismo vivir en un conventillo con 300 habitaciones que en uno de 20 o vivir en una habitación oscura en vez de conseguir una que tuviera una ventana a la calle y que permitiera promocionar tareas artesanales. Los contratos se estipulaban por períodos de seis meses, sin embargo los reglamentos de los inquilinatos establecían un mínimo de tres días de preaviso para retirarse de la habitación, lo que permite deducir que era frecuente vivir en una vecindad por períodos de pocos meses. En muchos casos, la movilidad se producía hacia otro conventillo por lo que la vida en ellos podía durar más de una generación. Sin embargo no se puede negar que haya sido vista como una forma de vida transitoria ni tampoco la única forma de habitación de los sectores populares: la vivienda unifamiliar y un conjunto de soluciones muchas veces ocasionales fueron modos difundidos de habitar.

\section{VALORES Y PREJUICIOS RESPECTO A LA CASA PROPIA}

Diego Armus y Jorge Enrique Hardoy han afirmado que «el ideal de la casa propia fue afirmándose como un dato cultural de la realidad urbana argentina» ${ }^{31}$. Aunque a grandes rasgos coincido con esta afirmación, me parece importante observar con más detalle cuál es el ideal que aparece en las fuentes de la huelga de inquilinos, ideal que está íntimamente ligado a las formas familiares a las que se aspira. Existen pocos datos directos de lo que pensaban los mismos inquilinos, aunque sí hay cartas enviadas a la prensa obrera, probablemente de aquellas personas más comprometidas con los movimientos políticos. Veamos

31. Véase Armus, Diego y Hardoy, Jorge Enrique: "Conventillos, ranchos y casa propia en el mundo urbano del novecientos», en Diego Armus (comp.): Mundo Urbano y cultura popular, Buenos Aires, Sudamericana, 1990, pp. 153-193. 
qué dice la prensa, cuyas visiones no son tan coincidentes como en el caso del higienismo.

Caras y Caretas proponía la construcción de una casa sobre un terreno en los barrios a los que llegaba el ferrocarril. Tendría una "fachada elegante», una sala, dos habitaciones, cocina, baño, patio, jardín «lleno de aire, de luz y de sol; invitando a la alegría al goce de vivir» ${ }^{32}$. Es evidente que este modelo estaba destinado a las clases medias o en todo caso a los artesanos calificados; sin embargo la nota periodística finaliza afirmando, con gran asombro, que cualquiera podía acceder a ella pagando cuotas del mismo precio que un alquiler, durante diez años. Estas propuestas que estimulaban la libre competencia individual y de libre juego de la oferta y la demanda fueron los modelos que prevalecieron en el largo plazo, aunque no todos estaban de acuerdo.

Hacia el final de la huelga, el socialismo se opuso a ella porque consideraba que la solución al problema no era la disminución de los precios de alquiler sino la construcción de más viviendas.

«Hay que construir muchas viviendas cómodas y baratas. Hay que estimular y fomentar por todos los medios la edificación de casas para obreros, o para hombres, como alguien dijo (...) para realizar el ideal de la vivienda obrera sana, higiénica, amplia y barata, para acabar con la monstruosa llaga social que se llama 'conventillo'».

Para los socialistas el modelo de hogar era la vivienda unifamiliar a la que se debía acceder por medio de cooperativas como el Hogar Obrero, fundada en 1905. Las características de la vivienda ideal eran las opuestas a las derivadas de las denuncias respecto a los conventillos: "después de treinta años de acción socialista, [que] nuestros obreros habitasen dos piezas amplias, higiénicas, llenas de aire y de sol, en vez de la actual pieza estrecha, oscura y sucia, foco de corrupción física e intelectual» ${ }^{33}$.

Sin embargo ésta no es la visión del anarquismo, quien a pesar de tener una postura más radical respecto a la utopía social sin clases ni estado, desarrolló prácticas culturales que iban desde pic-nics los domingos hasta la activa participación en los reclamos femeninos y en la huelga de inquilinos. Una editorial de La Protesta declaraba "iNo exigimos casas para obreros, exigimos habitaciones para hombres!»34. Es decir, se adhirieron al reclamo concreto de mejoras en los conventillos. También es interesante señalar el uso de metáforas que utilizan términos de la construcción en sentido social:

"las tendencias radicales del pensamiento moderno que no ha venido a la escena para apuntalar edificios en bancarrota sino demoler y edificar de nuevo. '¡Casas para obreros!' nos gritan ahora. Como si los obreros necesitaran tutores que les hicieran casas, tal y como a las bestias se les hacen galpones o cabañas» ${ }^{35}$.

32. Caras y Caretas, n 389, 17 de marzo de 1906 (en Fraser, Howard M.: Op. cit., p. 129).

33. "El problema de la habitación», La Vanguardia, año XIV, n 618, 24 de noviembre de 1907, p. 1 (en Reinoso, Roberto (comp): Op. cit., p. 61).

34. La Protesta, $\mathrm{n}^{\circ}$ 1154, 4 de octubre de 1907, p. 1 (en Spalding, Hobart: Op. cit., p. 485).

35. Ibíd. 
Como contraposición a la imagen de las familias desalojadas, es interesante analizar una orden de desalojo que incorporaba a una familia como demandante «en el juicio seguido por Don José Agustín Novaro, Nila Baliño de Graci y sus hijos menores contra Don Antonio Mauro» ${ }^{36}$. Es extraño que un niño pueda aparecer como demandante; es evidente que hay una fuerte necesidad de legitimar el desalojo como si fuera una necesidad familiar ya que, como he señalado, la opinión pública se conmovía ante la problemática de los sectores populares, que obviamente tenía consecuencias epidémicas en la vida de todos los ciudadanos.

Por último hay que señalar que aunque generalmente en una habitación podían convivir amigos, compañeros o incluso personas desalojadas de otras habitaciones, La Voz de la Iglesia consideraba que los habitantes de una habitación de conventillo pertenecían a una misma familia: "fue desalojado Santiago Rivas, familia compuesta de diez personas». También se señalaba la muchas veces disminuida jefatura femenina: «dos piezas ocupadas por María López y once miembros de su familia». A diferencia de los otros documentos, aquí aparecen los sectores populares con nombre y apellido. De todos modos la acción reformadora católica y las instituciones de beneficencia buscaban un proyecto de reforma social basado en el control y vigilancia de los sectores populares ${ }^{37}$. En el II Congreso Nacional de los Católicos Argentinos de 1907 se indicaba en relación a las obreras que «la mejor enseñanza y los más sanos consejos son por sí solos ineficaces para conseguir el objeto indicado, si no se les protege en el trabajo y se las coloca en condiciones materiales que posibiliten la conservación de su fe y su pudor» ${ }^{38}$.

\section{LA PARTICIPACIÓN DE LAS MUJERES EN LA HUELGA}

Además de las preocupaciones por evitar enfermedades contagiosas y mejorar las condiciones sanitarias de la ciudad, el otro aspecto fundamental que produjo la fuerte repercusión de la huelga de inquilinos fue la participación de las mujeres ${ }^{39}$.

Desde posturas ideológicas contrapuestas pero conscientes del papel fundamental de las mujeres en la vida social, los periódicos que llamaron la atención acerca del rol de las mujeres fueron La Protesta y La Voz de la Iglesia. Para comprender la postura de la Iglesia es importante tener en cuenta que, a partir de la encíclica Rerum Novarum de León XIII, se estimuló la creación de círculos

36. "La huelga de inquilinos. Una orden de desalojo», La Protesta, n 1168, 20 de octubre de 1907, p. 2 (en Spalding, Hobart: Op. cit, p. 478).

37. Un trabajo interesante, centrado en el período de 1920, acerca de la relación entre Iglesia y vivienda popular es el de BALLent, Anahí: «La Iglesia y la vivienda popular: la "Gran Colecta Nacional» de 1919» en Diego Armus (comp.): Mundo Urbano..., op. cit., pp. 195-217.

38. «II Congreso Nacional de los Católicos Argentinos de 1907» en SpaldinG, Hobart: Op. cit, p. 540.

39. A pesar de la insistencia de la prensa y de la fuerte visibilidad de las mujeres en las fotografías, los estudios acerca de los conventillos y sobre la huelga de inquilinos no han tratado la activa participación de las mujeres, como se ha señalado más arriba. 
obreros católicos con el objetivo de impulsar la doctrina cristiana entre los trabajadores que se habían adherido a los ideales socialistas y anarquistas. En este contexto, los reformadores católicos buscaban el apoyo de los huelguistas, por ello publicaron sin prejuicios los pliegos de condiciones y los llamados a la huelga.

No es llamativo que la pobreza de los conventillos fuera vista por la Iglesia con compasión y como signo de ciertas virtudes, pero además destacó el protagonismo de mujeres y niños y la unidad ante el conflicto: "los cantos proseguían; cada mueble era rodeado por un enjambre de sucios rapazuelos de todas las razas y de todas las naciones, que ayudaban a transportarlos juntamente con las mujeres, cuyo entusiasmo, si cabe, era mayor que el de los hombres ${ }^{40}$. Este periódico católico no puede ni quiere negar la participación femenina, sin embargo insiste en el papel de inocencia y subordinación de niños y mujeres, que implicaba la necesidad de protección. "Un reportaje» de un desalojo señalaba que, ante la intimación reglamentaria,

"la hija mayor de Rinaldi enseñó un documento humano, viviente, ante el cual los denunciantes tuvieron que renunciar a su desagradable mandato. En una de las camas, yacía enfermo un pobre niño, de mirada tierna y aspecto endeble. Su estado es grave y lo afirma un certificado médico, no era entonces posible proceder al lanzamiento ${ }^{41}$.

\section{La Protesta también destacaba el protagonismo femenino:}

«en la calle Defensa existe un conventillo cuyo encargado quiso sentar plaza de hombre guapo, golpeando bárbaramente a un muchacho de tierna edad. (...) A las valerosas mujeres, después de derribarlo al suelo impidiéndole todo movimiento, se les ocurrió la humorada de quitarle los calzones, largándolo en tal facha a la calle, provocando la risa de todos los espectadores de este curioso y divertido sainete ${ }^{42}$.

Desde esta perspectiva, niños y mujeres no eran vistos como desamparados sino que lograban echar a los encargados, evitar el cobro de alquileres y los desalojos gracias a su valentía. Incluso utilizaban distintas estrategias:

«el propietario de otro convento de la calle Chacabuco también se presentó llorando ante el comisario de la sección, exponiendo que no era posible la permanencia en su casa debido a la hostilidad de las mujeres que lo maltrataban de palabra y de acción, escupiéndole la cara de avaro que tiene, y no dejándole dormir sueño tranquilo, amenazándole con quitarle la roña mediante un baño de agua hirviendo si no se decide a efectuarles la rebaja del $30 \%$ en el precio de los alquileres ${ }^{43}$.

En un trabajo acerca de las relaciones entre género y poder, Joan Scott señala que en el siglo XIX el concepto de clase contaba con el género en su enunciado.

40. La Voz de la Iglesia, n 7308, 1 de octubre de 1907, p. 1 (en Spalding, Hobart: Op. cit, p. 480).

41. Ibíd.

42. La Protesta, 12 de octubre de 1907 (en Spalding, Hobart: Op. cit, p. 482).

43. Ibíd. 


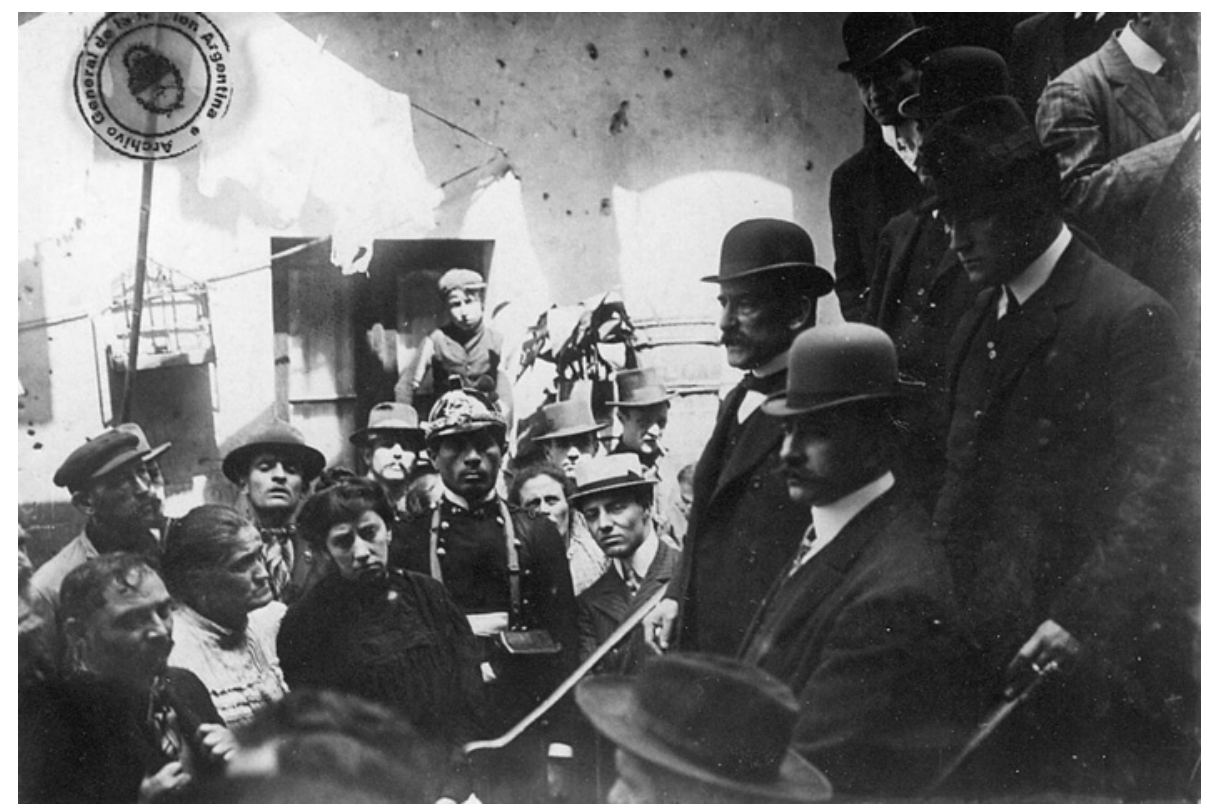

Huelga de conventillos, Colección Caras y Caretas, AGN, 1907.

Por ejemplo los reformadores de la clase media describieron a los trabajadores en términos codificados como femeninos (subordinados, débiles, explotados sexualmente) y los dirigentes del trabajo replicaron insistiendo en la posición masculina de la clase trabajadora ${ }^{44}$. Esta respuesta es evidente en un manifiesto de la huelga de inquilinos de 1907 que invoca: "iipueblo viril!!, en ti está el que esta huelga comenzada con un éxito augurador de un próximo triunfo se haga general». Sin embargo, a este llamado acudieron sobre todo las mujeres y, más que a consignas abstractas, ellas respondían con actos cotidianos. El éxito de la suspensión del pago de los alquileres durante los meses que duró la huelga se debe a las mujeres, quienes lograron, a través de múltiples estrategias, detener a los caseros.

Las mujeres no sólo lograron impedir la actuación de los cobradores sino que otorgaron visibilidad al conflicto. Como ya se ha mencionado, la opinión de los periódicos analizados no se manifestaba en contra de los huelguistas. Al contrario se justificaba por las malas condiciones a las que se exponían mujeres y niños. El momento de mayor éxito de la huelga se dio cuando las mujeres organizaron "la marcha de las escobas» para «barrer a los caseros». Unas fotos, publicadas por Caras y Caretas, muestran este evento. Es interesante destacar

44. ScotT, Joan W.: «El género: una categoría útil para el análisis histórico», en James Amelang y Mary Nash (comps.): Historia y Género: Las mujeres en la Europa Moderna y Contemporánea, Valencia, Ed. Alfons el Magnanim, 1990, p. 53. 


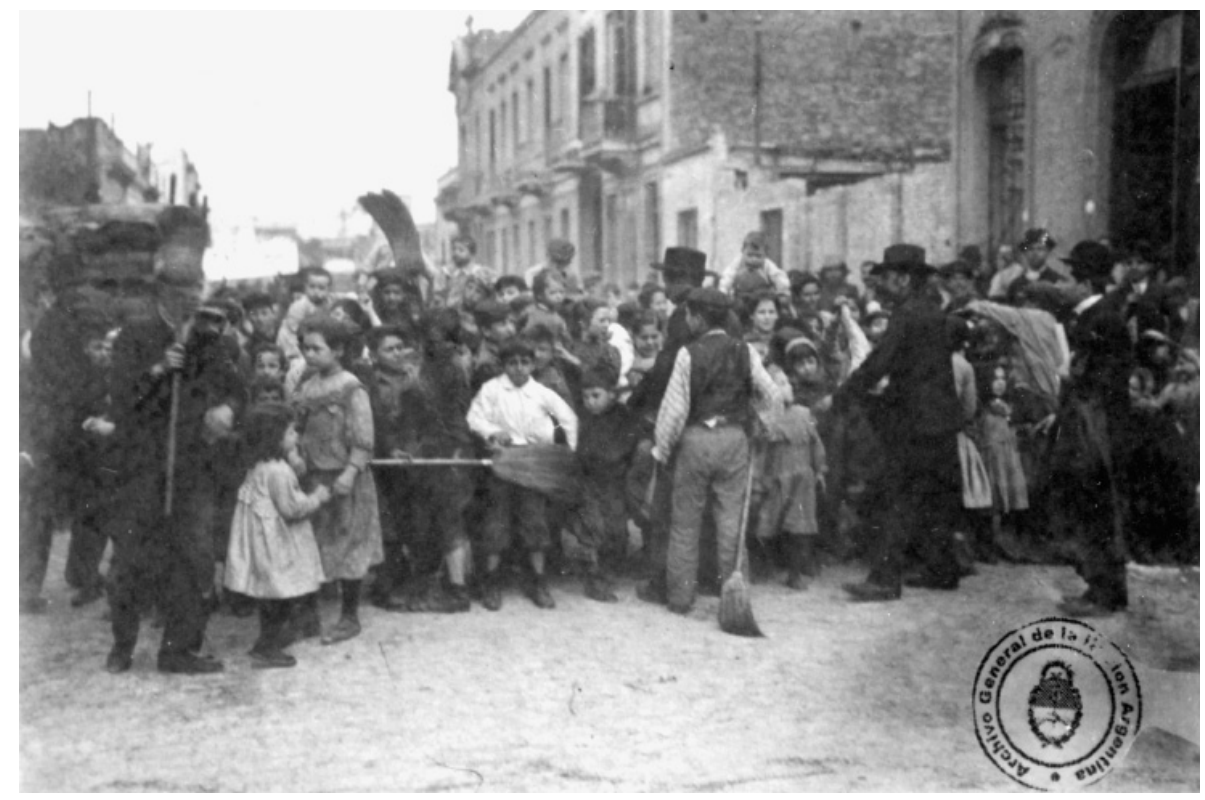

«Marcha de las escobas». Huelga de conventillos, Colección Caras y Caretas, AGN, 1907.

que la misma organización de la marcha evidencia la conformación de lazos entre mujeres. Otras fuentes relativas a la vida en los conventillos resaltan las disputas que se podían crear por el lavado de ropa o los gritos y discusiones que se escuchaban a través de las paredes de las habitaciones y en los patios; sin embargo una mirada detenida a las fotos muestran la unión entre las mujeres. Es interesante señalar el papel simbólico de la escoba como instrumento fundamental que se utilizó para dar publicidad a este problema.

Además la marcha implicó la apropiación de un espacio público: la calle. Sin embargo me parece importante aclarar que no se trató de la ocupación de un espacio público considerado masculino por grupos de mujeres que pertenecerían a espacios privados domésticos, sino que existía cierta continuidad que iba del patio del conventillo a la calle y el barrio. Los conventillos propiciaban la sociabilidad y además las malas condiciones de habitabilidad provocaban que gran parte del día se pasara en la calle.

Por otro lado, el ideal de la casa unifamiliar todavía no había obtenido el consenso al que se aspiraría a partir de los años veinte. En ese período lo urgente era mejorar las mismas condiciones de higiene de los conventillos y las mujeres participaron activamente haciendo visible sus reclamos concretos.

En el proceso del movimiento de protesta, la experiencia de organización de reclamos concretos, acorde con las problemáticas inmediatas aportó formas de identificación comunes y significados de acción colectiva. Esta búsqueda por la disminución del costo de alquiler y las mejoras habitacionales tuvieron un fuer- 
te impacto en la opinión pública, que a diferencia de la mayoría de las huelgas del período, se inclinó favorablemente hacia las y los huelguistas.

\section{CONCLUSIONES}

En este trabajo he intentado destacar las distintas visiones que se dieron en la época respecto a la huelga de inquilinos, particularmente analizando las expresiones de la prensa escrita y de las fotografías publicadas. Se trata de una huelga de características particulares, que no tuvo lugar en el centro de las luchas obreras, como podía ser el puerto, eje de la producción primario-exportadora argentina, sino en el corazón de la vida cotidiana; no fue por tanto una huelga relacionada con la producción sino con el consumo de los trabajadores.

Se puede diferenciar la prensa obrera de aquella relacionada con posturas reformistas tanto de las élites como de las sociedades de beneficencia y el higienismo. Dentro de la prensa obrera se distinguen dos posturas ideológicas en pugna, el anarquismo y el socialismo. Cada una de ellas tuvo una posición propia respecto a la huelga; mientras que los anarquistas participaron activamente, destacaron el papel de las mujeres y promocionaron la necesidad de reducir el precio del alquiler y de obtener mejoras higiénicas, los socialistas se opusieron al reclamo porque consideraban que la rebaja del alquiler no era una solución revolucionaria; lo que se debía conseguir era la construcción de casas para obreros en forma de cooperativas. Tampoco el socialismo se interesó por la participación femenina.

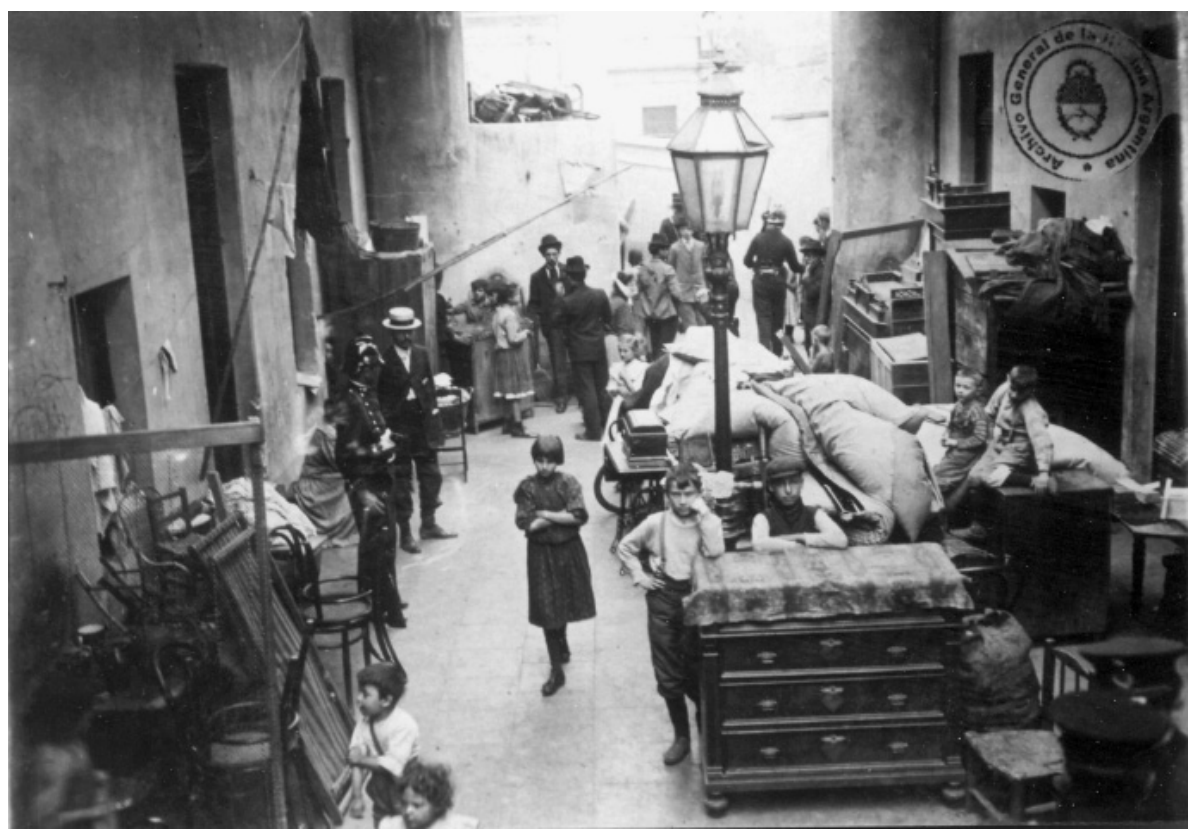

Huelga de conventillos, Colección Caras y Caretas, AGN, 1907. 
La Nación respondía a los intereses de las élites dirigentes; sin embargo justificó los reclamos y demandó intervención estatal. Caras y Caretas también reclamó la acción estatal pero al utilizar las fotografías como medio de expresión no pudo ocultar la fuerte actuación femenina ante la presencia policial y en la marcha de las escobas; así se convirtió en un espejo de los niños, mujeres, patios, y objetos de la cultura material existente en los conventillos.

Por último, La Voz de la Iglesia aceptó la legitimidad del reclamo, difundió la información de las organizaciones obreras y se propuso como guía de los humildes y desposeídos, principalmente de las mujeres.

Es importante concluir que aunque se encuentren profundas diferencias entre ideologías y posturas, existió un fuerte consenso respecto a la legitimidad del reclamo. Los propietarios no mejoraban las condiciones higiénicas de las viviendas y cobraban precios excesivamente altos, perjudicando sobre todo a las mujeres y niños.

Aunque se realizaron pocas medidas para la construcción de viviendas, la opinión pública se manifestó a favor de una política para responder a la cuestión social. Los distintos periódicos, incluido La Nación, pedían a la Municipalidad y al Ministerio del Interior que tomara cartas en el asunto.

A pesar de la falta de reformas concretas para paliar los problemas de hacinamiento, considero que los nuevos ideales de familia y vivienda fueron concebidos en contraposición a las críticas de oscuridad, insalubridad y promiscuidad de la única habitación familiar utilizada en los conventillos, proponiendo casas con dos habitaciones para distinguir el tipo de actividades a realizar dentro del hogar y mucho aire y luz.

En el proceso finisecular de transformaciones estructurales, los conceptos de género, familia y vivienda todavía no se habían modificado por completo. Joan Scott ha negado la coincidencia entre espacio privado, doméstico y femenino en oposición a un espacio laboral y público, propio de los hombres, entre los trabajadores textiles de la Francia de 1830 y 1840. Tanto hombres como mujeres calificados trabajaban fuera del hogar, mientras que los hombres que lo hacían en sus casas cobraban salarios menores y debían trabajar sin descanso ${ }^{45}$.

En el caso de Buenos Aires, en 1907, las concepciones respecto a los sectores populares no consideraban una separación tajante de los ámbitos doméstico femenino vs. público masculino. En los conventillos faltaba la intimidad de la vivienda unifamiliar y existía una fuerte sociabilidad que permitió la solidaridad y la unión entre las mujeres durante el conflicto. La opinión pública fijó sus ojos sobre las mujeres enfrentándose a los policías para evitar los desalojos, las vieron recorrer las calles, empuñando sus escobas, las escucharon reclamando mejores condiciones de vida y les dieron la razón.

45. ScotT, Joan Wallach, «Work identities for Men and Women. The politics of work and family in the Parisian garment trades in 1848", en Gender and the Politics of History, New York, Columbia University, 1988, pp. 92-112. 
La importancia que he atribuido a la «marcha de las escobas» obedece a que fue el símbolo que utilizaron las mujeres para otorgar visibilidad a su reclamo. El énfasis de los trabajos preocupados por los resultados de las luchas obreras o por la actividad del Estado dejaron de lado los problemas de la vida cotidiana. La cuestión de la vivienda vista desde esta perspectiva ha permitido observar el consenso de la opinión pública para buscar soluciones favorables a los sectores populares. Aunque la fuerza del libre mercado fue irresistible y las medidas concretas de construcción nunca tuvieron gran importancia, la unidad de criterios respecto al hacinamiento y la higiene influyeron en los posteriores desarrollos respecto a los ideales de la vivienda y a las virtudes familiares. Poner el énfasis en los resultados exitosos muchas veces ha oscurecido algunos procesos importantes. En este caso, una huelga de consumidores, que no pretendía un cambio revolucionario consiguió mayor participación, repercusión y hasta cierto punto influencia en las concepciones que se formarían en los años siguientes. 